\title{
Cervical screening and health inequality in England in the 1990s
}

\author{
D Baker, E Middleton
}

J Epidemiol Community Health 2003;57:417-423

See end of article for authors' affiliations

.....................

Correspondence to: Professor D Baker, Institute of Public Health Research and Policy, University of

Salford, Humphrey Booth

House, The Crescent,

Salford M5 4QA, UK;

d.baker@salford.ac.uk

Accepted for publication 14 November 2002
Study objectives: To examine changing inequality in the coverage of cervical screening and its relation to organisational aspects of primary care and to inequality in cervical cancer incidence and mortality.

Design: Retrospective time trends analysis (1991-2001) of screening coverage and cervical cancer incidence and mortality in England.

Setting: The 99 district health authorities in England, as defined by 1999 boundaries were used to create a time series of incidence and mortality rates from cervical cancer per 100000 population. A subset of 60 district health authorities were used to construct a time series of screening coverage data and GP and practice characteristics. Health authorities were categorised into one of three "deprivation" groups using the Townsend Deprivation Index.

Participants: Women aged $<35$ and 35-64 were selected from health authority populations as the main focus of the study.

Results: Cervical cancer screening coverage was consistently higher in affluent areas from 1991-9 but ratio rates of inequality between affluent and deprived health authorities narrowed over time. The increase in coverage in deprived areas was most closely associated with an increase in the number of practice nurses. Cervical cancer incidence and mortality rates were consistently higher in deprived health authorities, but inequality decreased. Screening coverage and cervical cancer rates were highly negatively correlated in deprived health authorities.

Conclusion: A primary health care intervention such as an organised programme of cervical screening can contribute to reducing inequality in population health.
C urrent health policy in the United Kingdom brings sharply into focus the central role of primary care in improving population health and tackling health inequality. ${ }^{12}$ However, a predominant and well established view among public health academics and professionals is that health care in itself has little bearing on improvements to population health and that the most important determinant of health inequality is income inequality, its effect on health being mediated by behaviours such as smoking, poor diet, and alcohol consumption..$^{3-6}$ The bedrock for this perspective has been laid by McKeown's powerful demonstration ${ }^{7}$ that dramatic reductions in mortality from infectious diseases in the 19th and early 20th century preceded the introduction of vaccination and immunisation and could be directly linked to improved standards of living, which led to a better nourished population.

The link between improving socioeconomic circumstances and improving health is however less clear when the major causes of death-cancer and heart disease-are associated with a multitude of interacting social, economic, and behavioural factors that are likely to vary by age, across time and across cultures and to depend on the condition being studied. ${ }^{89}$ In this context research on patterns of mortality from causes that are amenable to medical intervention (avoidable mortality) has gone some way towards demonstrating the significance of health care as a factor in changing patterns of population health. ${ }^{10}{ }^{11}$ This work shows that, in the period since the mid-1950s, declines in mortality from amenable causes have been more rapid than those from nonamenable causes and that these differences can be attributed to the effects of health care. ${ }^{12}{ }^{13}$ Such studies are however somewhat speculative as they generally lack longitudinal data on changes in patterns of health care provision; it is thus not possible to draw direct links between changing patterns of provision and reductions in health inequality.

Studies that have directly evaluated changes in inequality after the introduction of preventive interventions have generally shown that preventive interventions are likely to increase health inequality because of higher uptake among affluent groups. ${ }^{14}{ }^{15}$ However, Victora ${ }^{16}$ has shown that a longitudinal perspective is fundamental in such evaluations as apparently contradictory results may be found at different stages of implementation. On the basis of child health studies in Brazil, Victora has proposed the "inverse equity" hypothesis to describe these stages. A new intervention is firstly picked up by the wealthy and as a consequence, the outcome improves rapidly among this group because high coverage is reached within a short time. The outcome measure then stabilises at a very low level among the wealthy because no further reductions are possible- the minimum achievable plateau has been reached. The outcome improves among the poor but more slowly than it did among the wealthy, as uptake of the intervention is slower, and as there is greater scope for improvement among the poor because of their higher baseline level; at this stage the inequity gap narrows. Using Victora's framework, we have examined changes in the coverage of cervical screening between affluent and deprived health authorities in England in the 1990s and their association with cervical cancer incidence and mortality.

\section{ORGANISATION AND UPTAKE OF CERVICAL SCREENING}

Cervical screening in the form of a Papanicolaou (Pap) smear provides the key to early detection and improved survival chances from cervical cancer. ${ }^{17}$ If pre-invasive cervical intraepithelial neoplasia is identified and treated, development of invasive cervical cancer can be avoided. A centrally 
organised National Health Service programme of screening was introduced in England and Wales in 1988 and since this time all women aged 20-64 have been invited for screening, with a recall interval varying between three and five years. ${ }^{18}$ Since 1990 general practitioners have received incentive payments for reaching $80 \%$ target levels of coverage for their registered populations ${ }^{19}$; achieving such targets is associated with general practitioner and practice characteristics such as the presence of a female partner, more practice nurses, and larger practice size..$^{20-23}$

Cervical screening has been clearly associated with reducing the incidence of, and mortality from cervical cancer, particularly when it is provided in an organised rather than opportunistic fashion. Accelerated reductions in the incidence of and mortality from cervical cancer in England and Wales in the early 1990s have been attributed to a more effective screening programme. ${ }^{24} 25$

The extent to which cervical screening has reduced inequality in health over this time period has not been measured. Since the inception of cervical screening in England, lower uptake of cervical screening and higher incidence and mortality rates for cervical cancer have been consistently found for women of lower socioeconomic status and those living in deprived areas. ${ }^{17}{ }^{26}$ Lower age at first intercourse, a higher number of sexual partners, smoking, and lower uptake of cervical screening are risk factors that have in the past been closely associated with lower socioeconomic status, but recently research has suggested that women with higher socioeconomic status are now more likely to have a higher number of sexual partners and differences in the uptake of screening associated with socioeconomic circumstances have diminished. ${ }^{17}{ }^{21}{ }^{26-28}$ Much of the research demonstrating these relations is however based on cross sectional studies, often conducted in a single locality. The relation between socioeconomic status and cervical cancer incidence and mortality does seem to be age specific and is not generally found for women under the age of $35 .{ }^{29}$ Neither is there any indication of social class differences in the uptake of cervical screening for this age group. ${ }^{30}$

In this study we hypothesise that (1) there will be a reduction in inequity in the coverage of cervical screening in England in the 1990s, (2) that changes in coverage will be associated with changes in the organisation of primary care, and (3) that inequality in cervical cancer incidence and mortality will decrease over this time period.

\section{METHODS}

Time series of incidence of cervical cancer per 100000 population (1991-1997) and mortality from cervical cancer per 100000 population (1991-1999) were created for all 99 health authorities in England, as defined by 1999 boundaries. These were the latest available data and were supplied by the Office for National Statistics (ONS). Rates were calculated by the ONS based on mid-year population estimates for each year. Incidence data are collected by regional cancer registries, who ascertain details of cancer diagnoses from hospitals and other sources in their areas and forward them to a central registerthe National Health Service Central Register.

Rates for all ages, for women $0-35$ years and those between 35-64 years were used for this study. Health authority populations were divided into three "deprivation groups" (deprived $(n=33)$, neither deprived or affluent $(n=33)$, and affluent $(n=33)$ using the Townsend Deprivation Index (TDI). ${ }^{31}$ This index is constructed using 1991 census variables\%households with no car, \%households with more than one person per room, \%households not owner occupied, and \%economically active people who are unemployed. The variables were standardised over all the health authorities and summed to form an overall deprivation score. The construction of a similar time series of data to examine changing pat- terns of cervical screening and their relation to GP practice characteristics was more complex because of changes in data collection procedures and area definitions over the time period studied. To overcome this problem 60 of the 99 health authority areas existent in 1999 were used. These were areas for which there was little geographical change over the time period. The 60 areas were then grouped into three categories: deprived (20 areas, TDI $=1.27$ to 10.59$)$ neither deprived nor affluent (20 areas, TDI $=-2.41$ to 1.13 ), and affluent (20 areas, $\mathrm{TDI}=-4.5 \mathrm{l}$ to -2.79 ). All 20 of the deprived areas were contained within the group of 33 deprived areas for England, as described above. Eighteen of the affluent areas were contained within the group of 33 affluent areas for England, the two remaining sample affluent areas being ranked 36 and 39 for England as a whole.

Screening coverage was measured for each of the 60 health authorities by the percentage of GPs achieving the target of $80 \%$ of women aged 25-64 screened. A GP receives a target payment if $80 \%$ of eligible women on the practice list have had an adequate smear test during the previous five years. Information was also collected about GP and practice characteristics associated in other studies with variation in screening coverage. These were \% lone practitioners, \% GPs aged 65 and over, \% GPs with list size $>2500$, number of GPs per 10000 registered population, number of practice nurses per 10000 registered population, \% practices with at least one female GP, $\%$ practices with an approved trainer (practices responsible for training GPs as part of their qualification), average number of GPs per practice, and list inflation (inflation attributable to overestimation of the registered population relative to the population resident in an area).

\section{Analysis}

(1) Inequality in the distribution of cervical screening Inequality in target achievement between the deprived and affluent groups of areas was calculated as the ratio of the mean value of the coverage target variable for the deprived group to the mean value for the affluent group. As changes in inequity depend on rates of change of target achievement in each group, mean rates of change were also estimated. To test for a significant difference in the means of the two groups a $t$ test was carried out on estimated rates of change for individual areas in each group. The estimated rate of change for an individual area was found by fitting a regression line to target achievement values for the nine years. Similarly, measures of inequality were calculated for the GP and practice variables, changes in inequality over time examined, and rates of change compared in affluent and deprived groups.

To investigate the relation between high target levels and GP and practice characteristics, three cross sectional analyses were carried out for 1991, 1995, and 1999. For each of these three years regression analysis was used to identify deprivation, GP and practice variables that predicted target achievement.

Changes over time were examined separately for the affluent and deprived groups of areas. For each group a cross sectional time series fixed effects regression model was fitted. The fixed effects "within area" model explains how the variation in each individual area response is related to variation in the predictors for that area.

\section{(2) Inequality in the incidence of and mortality from} cervical cancer

The percentage change in incidence of and mortality from cervical cancer was calculated for each of the three "deprivation" groups of health authorities from 1991-7 for incidence and from 1991-9 for mortality. Log variance was used to estimate inequality between affluent and deprived health authorities at each time period and its change over time. 


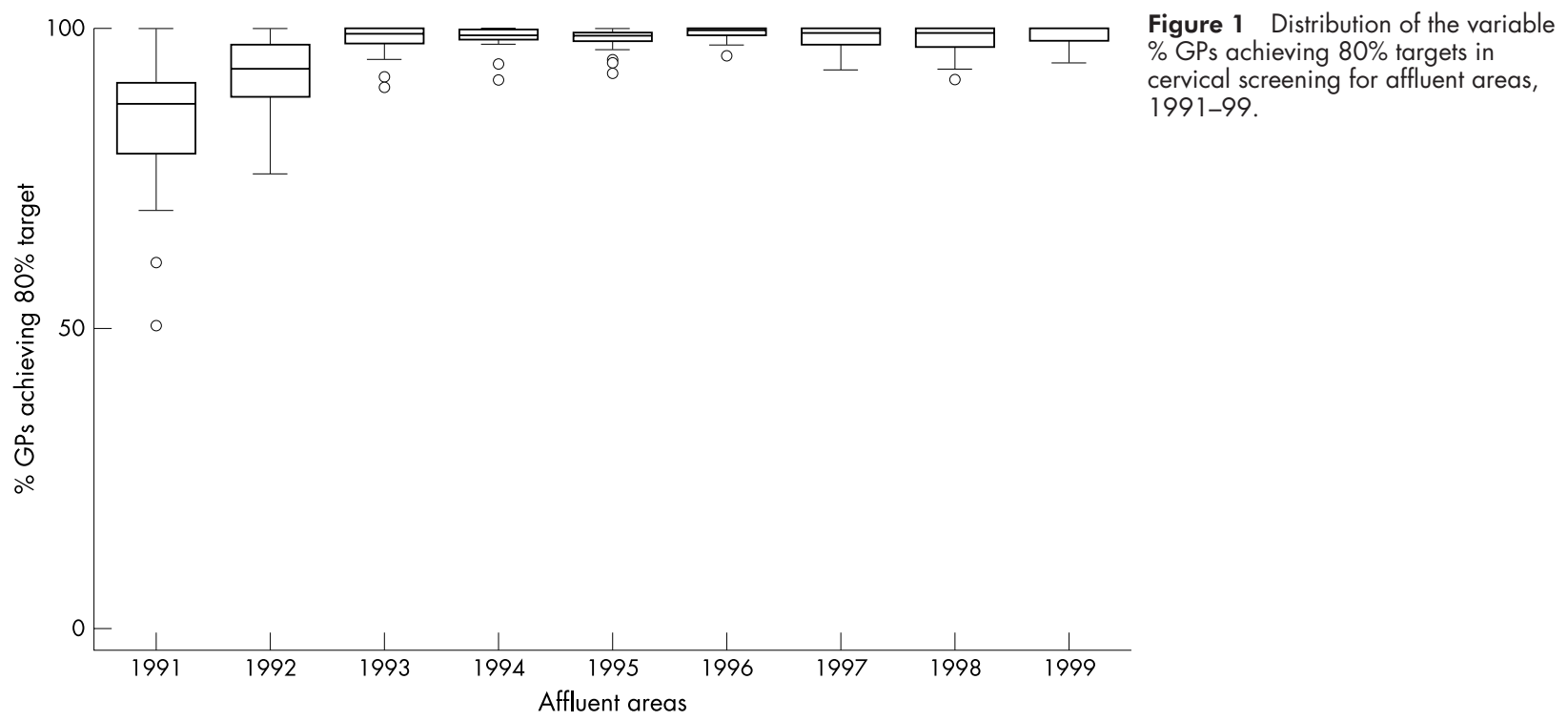

(3) Association between inequality in screening activity and cervical cancer

To examine the relation between area deprivation, screening activity, and cervical cancer, the average value of target achievement was taken for affluent areas $(n=20)$ and for deprived areas $(n=20)$ for each year. Similarly the incidence of and mortality from cervical cancer were calculated for all ages, $<35$ and 35-64 and for all available years. Scatter plots were drawn of cervical cancer incidence and mortality against screening coverage for affluent and deprived areas separately and the correlation coefficient calculated.

\section{RESULTS}

\section{Inequality in the distribution of cervical screening}

\section{between deprived and affluent areas}

Affluent and deprived groups of areas had markedly different distributions for the coverage target variable. Affluent areas had high levels of target achievement and variation within the group was small, especially in the years 1993-1999. The group of deprived areas was much more diverse and levels of target achievement were in general lower than in affluent areas. Both groups showed a rapid improvement in target achievement in the years 1991-1993 (average rate of change of mean values: $6.93 \%$ for affluent, $11.63 \%$ for deprived). Over the nine years the mean rate of change of target achievement was $1.27 \%$ per year for the affluent group and $4.04 \%$ per year for deprived groups, a significant difference in the means for the two groups $(t=6.1, \mathrm{p}=<0.001)$. (Figs 1 and 2$)$.

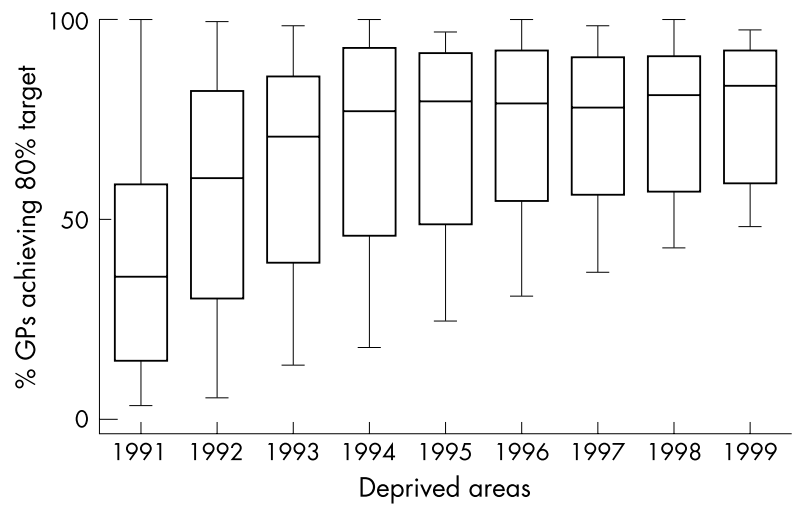

Figure 2 Distribution of the variable \% GPs achieving 80\% targets in cervical screening for deprived areas, 1991-99.
Table 1 shows mean values and inequality ratios for the years 1991-1999. As affluent areas reached and maintained maximum levels of target achievement, inequality ratios increased towards unity and inequity decreased.

\section{The role of primary care services in the coverage of cervical screening \\ Cross sectional analysis}

For each of the three years for which a cross sectional analysis has been carried out, the coverage target variable was correlated with all the GP and practice variables included in the study. After a stepwise forward selection regression analysis the GP and practice variables found to be significant in the model were "list inflation", "\% lone practitioners", "\%GPs aged 65 and over" (1995 and 1999 only), and "number of practice nurses per 10000 registered population" (1991 only). For each year of the analysis, relations between the outcome and predictor variables were the same for both affluent and deprived groups of areas. Values of the lone practitioner variable were in general lower in affluent areas than in deprived areas. Ratio measures of inequality for each of the GP and practice variables showed that inequality increased over time for "\% practices with at least one female $\mathrm{GP}^{\prime \prime}$ where mean values for the deprived group have remained at a fairly constant low level (an average rate of change of mean values of $0.59 \%$ per year) while the level in affluent areas has increased steadily (an average rate of change of mean values of $1.39 \%$ per year). Inequality decreased for "list inflation" and "number of nurses per 10000 registered population" (table 2 ).

\section{Longitudinal analysis}

Results of the cross sectional time series fixed effects models for affluent and deprived groups of areas are shown in table 3. Changes in the variables "\% GPs aged 65 and over", "number of nurses per 10000 registered population", and "list inflation" were most closely associated with changes in target achievement. The "\% lone practitioners variable" did not contribute significantly to the model because, within an area, changes in this variable over time are comparatively small.

The "number of nurses per 10000 registered population" was significant in the 1991 cross sectional model but not in models for 1995 and 1999. Over time, means for this variable in the affluent and deprived groups converged so that differences in 1991 were no longer apparent in 1999. 
Table 1 Mean values of the \%GPs achieving $80 \%$ targets in cervical screening for three deprivation groups and inequality ratios for 1991-1999

\begin{tabular}{llllll}
\hline Year & $\begin{array}{l}\text { Affluent mean } \\
\text { (SD) 20 areas }\end{array}$ & $\begin{array}{l}\text { Neither mean } \\
(\text { SD) 20 areas }\end{array}$ & $\begin{array}{l}\text { Deprived mean } \\
\text { (SD) 20 areas }\end{array}$ & $\begin{array}{l}\text { All areas mean } \\
\text { (SD) 60 areas }\end{array}$ & $\begin{array}{l}\text { Inequality } \\
\text { ratio* }\end{array}$ \\
\hline 1991 & $84.09(12.29)$ & $58.39(24.46)$ & $39.03(27.93)$ & $60.87(28.84)$ & 0.46 \\
1992 & $92.08(6.73)$ & $70.15(20.91)$ & $55.16(28.08)$ & $72.76(25.21)$ & 0.60 \\
1993 & $97.94(2.85)$ & $78.63(17.82)$ & $62.29(27.35)$ & $79.62(23.70)$ & 0.64 \\
1994 & $98.33(2.19)$ & $84.73(15.01)$ & $67.72(25.72)$ & $83.86(20.94)$ & 0.69 \\
1995 & $97.87(2.11)$ & $85.20(14.03)$ & $68.43(25.00)$ & $83.83(20.34)$ & 0.70 \\
1996 & $98.85(1.63)$ & $88.15(11.60)$ & $71.70(23.49)$ & $86.23(18.67)$ & 0.73 \\
1997 & $98.00(2.64)$ & $87.55(11.71)$ & $72.90(19.88)$ & $86.15(16.78)$ & 0.74 \\
1998 & $97.85(3.01)$ & $87.68(11.83)$ & $74.05(18.40)$ & $86.53(15.93)$ & 0.76 \\
1999 & $98.60(2.11)$ & $89.35(10.92)$ & $76.00(17.80)$ & $87.98(15.15)$ & 0.77 \\
\hline
\end{tabular}

* Ratios are calculated as deprived mean/affluent mean with equality represented by a ratio of 1 .

Table 2 Mean values of GP $\ddagger$ and practice variables for affluent and deprived groups, 1991-1999

\begin{tabular}{|c|c|c|c|c|c|c|c|c|c|c|}
\hline & 1991 & 1992 & 1993 & 1994 & 1995 & 1996 & 1997 & 1998 & 1999 & $\begin{array}{l}\text { Change per } \\
\text { yeart }\end{array}$ \\
\hline \multicolumn{11}{|c|}{$\%$ Lone practitioners } \\
\hline affluent & 6.63 & 6.31 & 5.70 & 5.66 & 5.42 & 5.02 & 4.92 & 4.77 & 4.88 & -0.23 \\
\hline neither & 13.31 & 13.06 & 13.09 & 13.34 & 12.85 & 13.15 & 12.95 & 12.44 & 12.81 & -0.10 \\
\hline deprived & 18.99 & 18.96 & 18.45 & 19.19 & 18.91 & 17.55 & 17.38 & 17.61 & 17.54 & -0.23 \\
\hline * ratio & 2.86 & 3.01 & 3.23 & 3.39 & 3.49 & 3.49 & 3.53 & 3.69 & 3.59 & \\
\hline \multicolumn{11}{|c|}{$\%$ GPs aged 65 and over } \\
\hline affluent & 1.57 & 1.05 & 1.08 & 1.06 & 0.95 & 0.70 & 0.64 & 0.49 & 0.62 & -0.11 \\
\hline neither & 3.56 & 2.34 & 2.21 & 2.03 & 1.90 & 2.10 & 2.22 & 2.06 & 2.14 & -0.11 \\
\hline deprived & 4.62 & 3.21 & 2.68 & 2.46 & 2.70 & 2.55 & 2.65 & 2.89 & 2.97 & -0.13 \\
\hline *ratio & 2.95 & 3.05 & 2.49 & 2.32 & 2.85 & 3.62 & 4.15 & 5.84 & 4.76 & \\
\hline \multicolumn{11}{|c|}{ List inflation (female) } \\
\hline affluent & 1.72 & 0.74 & 0.49 & 2.19 & 1.51 & 1.64 & 1.69 & 2.01 & 3.03 & 0.06 \\
\hline neither & 3.03 & 2.26 & 2.04 & 1.37 & 1.27 & 1.38 & 3.37 & 3.05 & 3.29 & -0.24 \\
\hline deprived & 10.00 & 9.65 & 9.56 & 7.81 & 7.71 & 7.01 & 7.02 & 7.13 & 5.50 & -0.57 \\
\hline * ratio & 5.81 & 13.04 & 19.51 & 3.57 & 5.11 & 4.27 & 4.15 & 3.55 & 1.82 & \\
\hline \multicolumn{11}{|c|}{ Number of GPs per 10000 registered population } \\
\hline affluent & 5.41 & 5.33 & 5.41 & 5.42 & 5.48 & 5.53 & 5.55 & 5.59 & 5.65 & 0.03 \\
\hline neither & 5.07 & 5.04 & 5.12 & 5.15 & 5.17 & 5.20 & 5.20 & 5.23 & 5.30 & 0.03 \\
\hline deprived & 4.96 & 4.89 & 4.92 & 5.00 & 5.00 & 5.06 & 5.08 & 5.12 & 5.22 & 0.03 \\
\hline * ratio & 0.92 & 0.92 & 0.91 & 0.92 & 0.91 & 0.91 & 0.92 & 0.92 & 0.92 & \\
\hline \multicolumn{11}{|c|}{ Number of practice nurses per 10000 registered population } \\
\hline affluent & 1.80 & 1.91 & 2.04 & 2.06 & 1.91 & 1.99 & 1.95 & 2.06 & 2.10 & 0.02 \\
\hline neither & 1.40 & 1.69 & 1.75 & 1.82 & 1.77 & 1.85 & 1.91 & 1.88 & 2.21 & 0.07 \\
\hline deprived & 1.35 & 1.51 & 1.59 & 1.74 & 1.63 & 1.93 & 1.94 & 1.98 & 2.05 & 0.09 \\
\hline * ratio & 0.75 & 0.79 & 0.78 & 0.85 & 0.85 & 0.97 & 0.99 & 0.96 & 0.98 & \\
\hline \multicolumn{11}{|c|}{$\%$ Practices with a female GP } \\
\hline affluent & 61.04 & 62.38 & 64.13 & 66.42 & 67.79 & 68.29 & 69.92 & 71.37 & 71.76 & 1.39 \\
\hline neither & 52.38 & 54.09 & 54.74 & 55.58 & 55.55 & 56.08 & 57.25 & 58.97 & 59.16 & 0.79 \\
\hline deprived & 47.94 & 48.50 & 48.52 & 49.68 & 50.17 & 51.36 & 51.70 & 51.50 & 52.57 & 0.59 \\
\hline *ratio & 0.79 & 0.78 & 0.76 & 0.75 & 0.74 & 0.75 & 0.74 & 0.72 & 0.73 & \\
\hline \multicolumn{11}{|c|}{$\%$ Practices with an approved trainer } \\
\hline affluent & 30.16 & 31.05 & 30.89 & 31.81 & 32.99 & 33.08 & 33.68 & 33.85 & 34.80 & 0.56 \\
\hline neither & 20.03 & 20.75 & 20.56 & 21.03 & 21.26 & 20.72 & 21.45 & 21.71 & 10.29 & 0.20 \\
\hline deprived & 13.26 & 13.55 & 13.70 & 14.26 & 15.21 & 15.78 & 16.10 & 16.32 & 16.91 & 0.49 \\
\hline * ratio & 0.44 & 0.44 & 0.44 & 0.45 & 0.46 & 0.48 & 0.48 & 0.48 & 0.49 & \\
\hline \multicolumn{11}{|c|}{ Average practice size } \\
\hline affluent & 3.37 & 3.45 & 3.48 & 3.54 & 3.59 & 3.64 & 3.69 & 3.75 & 3.75 & 0.05 \\
\hline neither & 2.78 & 2.80 & 2.79 & 2.84 & 2.86 & 2.85 & 2.87 & 2.90 & 2.89 & 0.02 \\
\hline deprived & 2.28 & 2.31 & 2.31 & 2.33 & 2.33 & 2.38 & 2.41 & 2.42 & 2.44 & 0.02 \\
\hline * ratio & 0.68 & 0.67 & 0.66 & 0.66 & 0.65 & 0.66 & 0.65 & 0.65 & 0.65 & \\
\hline
\end{tabular}

* Ratios are calculated as deprived mean/affluent mean with equality represented by a ratio of 1 . †Change per year is the mean of estimates for each area in the group found by regression analysis, rates of change significantly different ( $95 \%$ confidence levels) in both groups are shown in bold type. ‡GPs are unrestricted principals.

\section{Incidence of cervical cancer}

Table 4 compares incidence of, and mortality from, cervical cancer between affluent and deprived health authorities for 1991 to 1997 and 1991 to 1999 respectively. It shows that in all health authorities incidence of cervical cancer declined by $17.6 \%$ from $1991-3$ to $1995-7$ at all ages and by $19.9 \%$ for the 35-64 age group. Incidence rates were consistently lower in more affluent health authorities for all ages and for 35-64 year olds. For example in 1991-3 the mean incidence of cervical cancer for the 35-64 year old age group was 15.6/100 000 in affluent health authorities compared with 23.7/100 000 in deprived health authorities; in 1995-7 incidence rates were 13.2/100 000 and 18.7/100 000 respectively. Log variance shows that over the time period studied inequality in incidence rates between affluent and deprived health authorities declined. This was attributable to an accelerated decrease 


\begin{tabular}{|c|c|c|c|}
\hline Deprivation group/variable & Coefficient ( $p$ value) & $95 \% \mathrm{Cl}$ & $\begin{array}{l}r^{2} \text { (180 observations, } 20 \\
\text { areas) }\end{array}$ \\
\hline Affluent & & & 0.64 \\
\hline$\%$ GPs $65+$ & $-7.79(0.000)$ & $(-9.39$ to -6.19$)$ & \\
\hline GP65*year & $1.53(0.000)$ & $(1.20$ to 1.86$)$ & \\
\hline Nurses per 10000 registered population & $7.49(0.000)$ & (3.31 to 11.66$)$ & \\
\hline Nurses* year & $-1.06(0.001)$ & $(-1.70$ to -0.42$)$ & \\
\hline Year & $1.82(0.010)$ & $(0.44$ to 3.21$)$ & \\
\hline Neither & & & 0.73 \\
\hline$\%$ GPs $65+$ & $-3.04(0.000)$ & $(-4.44$ to -1.63$)$ & \\
\hline GP65*year & $0.42(0.000)$ & $(0.21$ to 0.64$)$ & \\
\hline Nurses per 10000 registered population & $9.83(0.000)$ & (5.13 to 14.54$)$ & \\
\hline Nurses* ${ }^{*}$ year & $-1.25(0.000)$ & $(-1.92$ to -0.57$)$ & \\
\hline List inflation (female) & $-1.40(0.000)$ & $(-1.96$ to -0.83$)$ & \\
\hline Year & $3.78(0.000)$ & $(2.28$ to 5.28$)$ & \\
\hline Deprived & & & 0.75 \\
\hline$\%$ GPs $65+$ & $-1.64(0.000)$ & $(-2.47$ to -0.80$)$ & \\
\hline Nurses per 10000 registered population & $20.20(0.000)$ & (12.65 to 27.76$)$ & \\
\hline Nurses* ${ }^{*}$ year & $-4.12(0.000)$ & $(-5.30$ to -2.95$)$ & \\
\hline List inflation (female) & $-0.70(0.001)$ & $(-1.10$ to -0.29$)$ & \\
\hline Year & $10.60(0.000)$ & (8.51 to 12.68 ) & \\
\hline
\end{tabular}

in incidence in deprived health authorities and was particularly evident for the 35-64 year old age group in the first half of the decade, when incidence rates declined by $11.1 \%$ in deprived health authorities, compared with $6.2 \%$ in affluent health authorities.

The pattern for women $<35$ was somewhat different. Incidence of cervical cancer was low for this age group and bore no consistent relation to relative affluence or poverty over the decade. Incidence was marginally higher for deprived when compared with affluent health authorities in 1991 (4.31/ 100000 ; to $4.24 / 100000$ ) - but marginally lower for these populations when compared with affluent health authorities in 1993-5 (4.08/100 000 to 4.75/100 000) and in 1995-7 (4.07/ 100000 to $4.21 / 100000)$. Given the small numbers, the observed differences have little meaning.

\section{Mortality from cervical cancer}

Table 4 shows that mortality from cervical cancer in England consistently declined from 1991-9 at all ages and for women aged 35-64, for whom mortality rates fell by 32\% from
7.82/100 000 to 5.29/100 000. Rates of mortality were higher in deprived health authorities when compared with those with predominantly affluent populations for both age groups over the whole time period. There was little indication of any substantial change in inequality in mortality from cervical cancer over this time period at all ages. However, for the 35-64 year old age group there was some reduction in inequality in the last quarter of the decade because rates of mortality decreased by $13.9 \%$ in deprived health authorities 1995-9 compared with $6.5 \%$ in health authorities with more affluent populations.

Mortality from cervical cancer for $<35$ year olds was comparatively low in both affluent and deprived health authorities. The relation between higher rates of mortality and relative deprivation changed over the time period; mortality was higher in health authorities with predominantly affluent populations in 1991-3 (AF: 0.66/100 000; DP: 0.65/100 000) but the reverse was the case in 1997-9 (DP 0.51/100 000; AF: $0.45 / 100000$ ). There was no consistent pattern of change in inequality over time, with rates of mortality decreasing by

Table 4 Cervical cancer incidence (1991-7) and mortality (1991-9) rates in deprived and affluent English health authorities

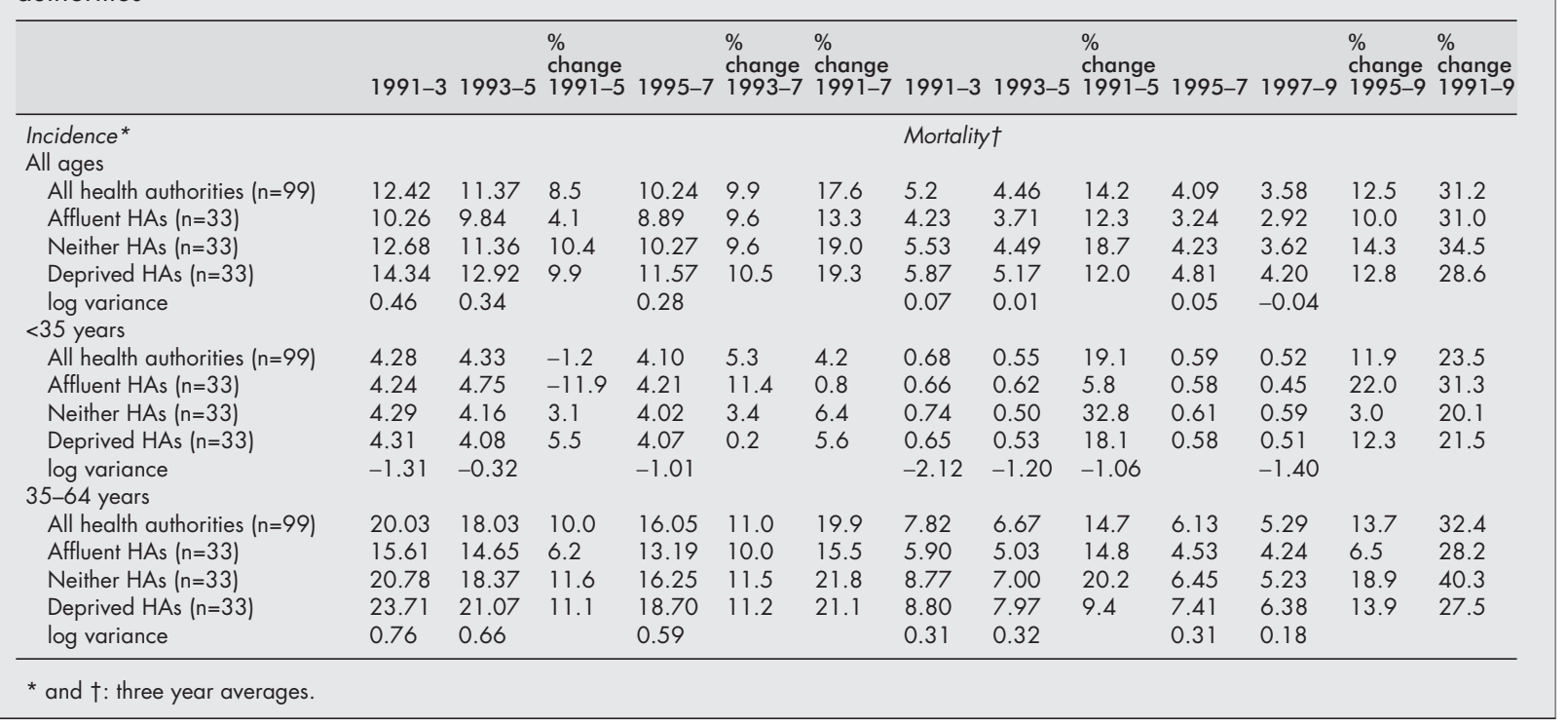


$18.1 \%$ between $1991-5$ in deprived health authorities, leading to a widening of inequality and decreasing by $22 \%$ between 1995-9 in affluent health authorities, leading to a narrowing of inequality in mortality.

\section{Association between inequality in screening activity and cervical cancer}

Correlation coefficients between coverage of cervical screening and cervical cancer showed that both the incidence of and mortality from cervical cancer was highly negatively correlated with coverage of cervical screening in deprived areas at all ages $(r=-0.98, \mathrm{p}<0.0035 ; r=-0.96,<0.0007)$ and at ages 35-64 $(r=-0.99, \mathrm{p}<0.0012 ; r=-0.91, \mathrm{p}<0.005)$. Trends were in a similar direction for women living in affluent areas, but did not reach significance either for all ages $(r=-0.68, r=-0.66)$, or at ages 35-64 $(r=-0.73, r=-0.73)$. Similarly the correlation coefficients for $<35$ year olds were not significant although there was a positive correlation between incidence and coverage in both affluent and deprived areas $(r=0.72, r=0.37)$ and a negative correlation between mortality and coverage $(r=-0.57, r=-0.69)$.

\section{DISCUSSION}

Our findings have shown a decrease in inequity in the coverage of cervical screening between affluent and deprived areas that reflects the final stage in Victora's ${ }^{16}$ inverse equity hypothesis. Introduction of the national cervical screening programme in 1988 has led to improvements in coverage target achievement in health authority areas in England in the 1990s. From 1991 to 1993 coverage target achievement in affluent areas improved at a slower rate than in deprived areas because they were approaching maximum levels. Coverage in deprived areas improved at a faster rate than in affluent areas from lower levels. From 1993 onwards, affluent areas maintained almost maximum levels of target achievement while achievement in deprived areas steadily improved. There were higher falls in list inflation and a greater increase in number of practice nurses per registered population in deprived compared with affluent areas from 1991-9, suggesting that these variables were most likely to account for changing inequity in cervical screening over the decade. List inflation is associated with population mobility and other studies have found that population mobility in urban and inner city areas is an important factor in explaining screening uptake rates. It leads to problems in maintaining accurate patient registers ${ }^{2021}$ and the more accurate the register, the more likely a patient is to be screened. In England the average size of GP practices has also increased and larger practices are likely to have better resources to employ nurses to carry out screening.

Our findings also indicate that changes in coverage of cervical cytology screening in England have had an impact on cervical cancer incidence, particularly in deprived areas and for women aged 35-64. Most of the gain in deprived health authorities occurred between 1991 and 1995, coinciding with the biggest improvement in the coverage of cervical screening.

Changes in inequality for mortality from cervical cancer were less marked over the decade as rates in deprived health authorities began to decline more sharply than those in affluent health authorities only in the last half of the decade. A longer time series is required to evaluate the extent to which such a narrowing of inequality in mortality from cervical cancer in the second part of the decade is maintained. The timing of this change would however be concomitant with the narrowing of inequality in incidence, which occurred in the first half of the decade. As the average five year survival rates for cervical cancer patients is close to $70 \%$ a change in incidence that was attributable to screening would not normally be observed in mortality data until five years later. ${ }^{32}$

\section{Key points}

- During the 1990s in England there was a reduction of inequity in the coverage of cervical screening between affluent and deprived areas.

- Changes in coverage over the decade were associated with changes in the organisation of primary care.

- Inequality in cervical cancer incidence and mortality also narrowed in the 1990s, particularly for women aged 35-64.

- It is encouraging that primary health care can have an impact on inequality; nevertheless women in deprived areas were the last to benefit from increased coverage.

Patterns of change in inequality for incidence of and mortality from cervical cancer were not replicated across all age groups targeted by screening. While an overall decline in incidence of cervical cancer was observed for women $<35$, there was no consistent relation between higher incidence and the relative affluence or deprivation of a health authority population. Similarly for mortality. This finding is in keeping with other studies of this age group and it could occur because cervical cancer is comparatively rare at this age and thus numbers were small and randomly distributed across health authorities. Alternatively genetic rather than social factors could have a greater effect on aetiology at these younger ages. ${ }^{33}{ }^{34}$ It could also reflect the fact that the uptake of cervical screening is less likely to be associated with socioeconomic status in younger women.

We cannot rule out the possibility that it was changes in the social distribution of other risk factors associated with cervical cancer that explained the narrowing of health inequality between affluent and deprived health authorities. But this seems unlikely, given the patterns of accelerated change observed in deprived areas. Changes in sexual or contraceptive practices between social groups would be more likely to effect a gradual change in cervical cancer incidence and mortality over time rather than the sharp changes over a comparatively short time periods in deprived areas. It is also the case that risky sexual behaviour has risen rather than fallen in the population as a whole and particularly for women in the 1990s, in terms of reporting two or more sexual partners in the last year and not using condoms. ${ }^{35}$ Smoking has increased rather than decreased for women in lower socioeconomic groups in the 1990s. ${ }^{36}$

The patterns of change observed here do not precisely follow the stages of Victora's inverse equity model, but are more characteristic of its final stage. Coverage of cervical screening has plateaued at maximum levels in the more affluent areas and cervical cancer incidence and mortality falls at a slow pace from comparatively low levels. Rapid improvements in the coverage of cervical screening in deprived areas are reflected in accelerated falls in cervical cancer incidence and mortality from higher levels, leading to a reduction in inequality. Our study emphasises the importance of the timing factor in interpreting changes in health inequality that are associated with primary care interventions; it also suggests two possible corollaries to the inverse equity hypothesis. The first is that, even for a single condition such as cervical cancer, the extent to which a health care intervention can have an impact on health inequality will be age specific and depend upon the aetiology of the condition at a particular age, and associated risk factors. The second and related point is that once an area reaches full coverage of screening for the target condition and a plateau of maximum coverage is reached, mortality may reach such a low level that the link between socioeconomic status and health outcomes is loosened and eventually lost. For example, Illsley and Le Grand ${ }^{37}$ have shown that despite continuing economic inequality between the northern and southern regions of Great Britain from the 
1950s to the present day, there is now no north/south gradient for deaths under 35. They attribute this to the effectiveness of the NHS in eliminating the diseases of poverty in early childhood.

\section{Methodological issues}

Study of the change in the coverage of cervical screening between affluent and deprived health authority areas in England over time has necessarily entailed selecting a set of areas whose geographical boundaries have remained stable over the decade. The choice of areas has been constrained by frequent reorganisations of health provision during the decade, both at health authority level and at a lower level of geography, but the 60 health authorities selected for our analysis of cervical screening patterns are representative of England as a whole in terms of deprivation and screening coverage.

The findings in this paper rely on data collected by the regional cancer registries to represent incidence of cervical cancer. These data are not always a completely accurate reflection of incidence, as they only include detected cases that are reported; regional registration practices may also vary. ${ }^{38}$ Variation in registration practices has not however been linked to levels of deprivation of health authority populations, so there is no reason to suppose that this could account for observed changes in inequality over time. The Townsend Index was used to classify areas according to their relative deprivation and this is derived from 1991 census variables. We have thus assumed that the socioeconomic characteristics of district health authorities remained comparatively stable over the decade. This assumption is justified by the close correlation between more recent indicators of income and employment ${ }^{39}$ and the Townsend index at district health authority level.

\section{Policy implications}

This research is encouraging from one perspective, as it illustrates that preventive interventions based in primary care can reduce health inequality. But the pattern of change was indicative of a "top down" strategy whereby reductions in more affluent groups are followed only later by improvements in conditions among the poor. ${ }^{40}$ In this context health policy could reasonably be concerned with redressing the balance of inequality at an earlier time point in the cycle of prevention.

\section{ACKNOWLEDGEMENTS}

We would like to thank Professor Graham Dunn for his advice about statistical methods.

\section{Authors' affiliations}

D Baker, E Middleton, National Primary Care Research and

Development Centre, University of Manchester, UK

Funding: this research was funded by the Department of Health, UK.

Conflicts of interest: none.

\section{REFERENCES}

1 Department of Health. The new NHS: modern, dependable. London: HMSO, 1998.

2 Department of Health. Saving lives: our healthier nation. London: HMSO, 1999.

3 Morris J. Inequalities in health: ten years and little further on. Lancet 1990;336:491-3.

4 Davey Smith G, Blane D, Bartley M. Explanations for socioeconomic differentials in mortality: evidence from Britain and elsewhere. European Journal of Public Health 1994:4:131-44.

5 Fox J, Benezeval M. Perspectives on social variations in health. In: Benzeval M, Judge K, Whitehead, eds. Tackling inequalities in health: an agenda for action. London: King's Fund, 1995:10-21.

6 Wilkinson R. Unhealthy societies: the afflictions of inequality. London: Routledge, 1996.
7 Mckeown T. The role of medicine: dream, mirage or nemesis? Oxford: Blackwell, 1979.

8 Baker D, Illsley R. Trends in inequality in health in Europe. International Journal of Health Sciences 1990;1:89-1 11.

9 Illsley R, Baker D. Contextual variations in the meaning of health inequality. Soc Sci Med 1991;32:359-65.

10 Rutstein D, Berenberg W, Chalmers T, et al. Measuring the quality of medical care. N Engl J Med 1976;294:582-8.

11 Charlton JRH, Velez R. Some international comparisons of mortality amenable to medical intervention. BM 1986;292:295-301.

12 Mackenbach J, Looman C, Kunst A, et al. Post-1950 mortality trends and medical care:gains in life expectancy due to declines in mortality from conditions amenable to medical intervention in the Netherlands. Soc Sci Med 1988;27:889-94.

13 Mackenbach J. The contribution of medical care to mortality decline: Mckeown revisited. J Clin Epidemiol 1996;49:1207-13.

14 Hart N. Inequalities in health: the individual versus the environment Journal of the Royal Statistical Society Series A 1986;149:228-46.

15 Reading R, Colver A, Openshaw S, et al. Do interventions that improve immunisation uptake also reduce social inequalities in uptake. BM 1994;308: 1142-4.

16 Victora C, Vaughan J, Barros F, et al. Explaining trends in inequities:evidence from Brazilian child health studies. Lancet 2000;356:1093-8.

17 Fouquet R, Gage G. Role of screening in reducing invasive cervical cancer registrations in England. J Med Screen 1996;3:90-6.

18 Department of Health and the Welsh Office. General practice in the National Health Service: a new contract. London: HMSO, 1989.

19 Department of Health. Terms of service for doctors in general practice. London: HMSO, 1989.

20 Majeed FA, Cook D, Anderson HR, et al. Using patient and general practice characteristics to explain variations in cervical smear uptake rates. BM 1994;308: 1272-6.

21 Ibbotson T, Wyke S, McEwen J, et al. Uptake of cervical screening in general practice: effect of practice organisation, structure and deprivation. J Med Screen 1996;3:35-9.

22 Baker D, Klein R. Explaining outputs of primary care: population and practice factors. BMW 1991;303:225-9.

23 Leese B, Bosanquet N. Change in general practice and its effects on service provision in areas with different socioeconomic characteristics. BM 1995;311:546-50.

24 Sasieni $\mathbf{P}$, Cuzick J, Farmery E. Accelerate decline in cervical cancer mortality in England and Wales. Lancet 1995;346:1566-7.

25 Quinn M, Babb P, Jones J, et al. Effect of screening on incidence of and mortality from cancer of the cervix in England: evaluation based on routinely collected statistics. BM 1999;318:904-8.

26 Ibbotson T, Wyke S. A review of cervical cancer and cervical screening implications for nursing practice. Journal of Advanced Nursing 1995;22:745-52.

27 Murphy M, Mant D, Goldblatt P. Social class, marital status and cance of the uterine cervix in England and Wales, 1950-1983. J Epidemiol Community Health 1992;46:378-81.

28 Wright L, Harwood D, Coulter A. Health and lifestyles in the Oxford Region. Oxford: Health Services Research Unit, University of Oxford, 1992.

29 Cuzick J, Sasieni P, Singer A. Risk factors for invasive cervix cancer in young women. Eur J Cancer 1996;32A:836-41.

30 Coulter A, Baldwin A. Survey of population coverage in cervical cancer screening in Oxford region. Journal of the Royal College of General Practitioners 1987; 37:441-3.

31 Townsend P, Simpson D, Tibbs N. Inequalities in the city of Bristol: a preliminary review of statistical evidence. Int J Health Serv 1985; 15:637-63.

32 Lynge $\mathbf{E}$, Madsen M, Engholm G. Effect of organised screening on incidence and mortality of cervical cancer in Denmark. Cancer Res 2001:49:2157-60.

33 Draper G, Cook G. Changing patterns of cervical cancer rates. BM 1983;287:510.

34 Beral V, Booth M. Predictions of cervical cancer incidence and mortality in England and Wales. Lancet 1986;i:495.

35 Johnson AM, Mercer $\mathrm{CH}$, Erens B, et al. Sexual behaviour in Britain: partnerships, practices and HIV risk behaviours. Lancet 2001;358: 1835-42.

36 Walker A, Maher J, Coulthard M, et al. Living in Britain. Results from the General Household Survey. London: The Stationery Office, 2000.

37 Illsley R, Le Grand J. Regional inequalities in mortality. J Epidemiol Community Health 1993;47:444-9.

38 Dickinson HO, Salotti JA, Birch PJ, et al. How complete and accurate are cancer registrations notified by the National Health Service Central Register for England and Wales? J Epidemiol Community Health 2001;55:414-22.

39 DETR. Indices of deprivation 2000. London: DETR Regeneration Research Summary: Number 31, 2000

40 Gwatkin D. Health inequalities and the health of the poor: What do we know? What can we do? Bull World Health Organ 2000;78:3-18. 